\title{
The vectorcardiogram in mitral valve disease
}

\author{
John Hamer \\ From St. Bartholomew's Hospital, London E.C.I
}

The Frank system vectorcardiogram has been studied in 61 patients with severe mitral valve disease to determine the value of the vectorcardiogram in the recognition of the relative degree of left and right ventricular hypertrophy in this situation.

The appearance of the usual evidence of right ventricular hypertrophy is delayed in mitral valve disease by the vertical electrical position of the heart which may be due to alterations in the intrathoracic electrical field produced by left atrial enlargement.

Voltage criteria for the recognition of isolated left or right ventricular hypertrophy in the vectorcardiogram are not applicable to combined ventricular hypertrophy in mitral valve disease. The present analysis is based on the spatial pattern of the QRS loop.

The vectorcardiograms show a continuous gradation from posterior to anterior direction, the extremes indicating dominant left and right ventricular hypertrophy, respectively. Five groups are recognized from the appearance in the horizontal plane. Long posterior loops (Fig. I) are associated with severe left ventricular hypertrophy, open posterior loops (Fig. 2) with left ventricular dominance, and wide posterior loops (Fig. 3) with moderate hypertrophy of both ventricles. Wide crossed loops (Fig. 4) indicate right ventricular dominance, and anterior clockwise loops (Fig. 5) are found with severe right ventricular hypertrophy.

The vectorcardiogram rarely showed large $Q R S$ voltages in left ventricular hypertrophy, though these changes were often evident in the conventional electrocardiogram. The vectorcardiogram appeared to be more successful than the electrocardiogram in the recognition of severe right ventricular hypertrophy. An unusual rightwards displacement of the QRS loop was found in patients with tricuspid valve disease.

It is concluded that the vectorcardiogram gives useful additional information for the recognition of ventricular hypertrophy that is not evident in the conventional electrocardiogram in mitral valve disease.

The scalar electrocardiogram is often unhelpful in the assessment of left and right ventricular hypertrophy in patients with mitral valve disease (Fraser and Turner, 1955; Imperial, Bendezu, and Zimmerman, 1960). The vectorcardiogram allows more detailed analysis of the distribution of electrical forces during the course of ventricular activation. In the present study the changes in the spatial QRS loop of the vectorcardiogram have been analysed in 6I patients with mitral valve disease, using the Frank (1956) electrode system. The findings have been correlated with the degree of ventricular hypertrophy determined by clinical assessment and special investigation.

\section{Methods}

The $6 \mathrm{I}$ patients were studied in hospital while the possibility of surgical treatment for their mitral valve disease was being considered. The

Received 3 June 1969. results of clinical examination, cardiac catheterization, and angiocardiography were taken into consideration in reaching the final diagnosis, and in many cases the valve changes were confirmed at subsequent operation. Left and right ventricular hypertrophy were separately assessed as severe $(t+)$, slight $(t)$, or absent $(0)$ from the clinical findings and the results of the special investigations without reference to the electrocardiogram or vectorcardiogram.

Conventional scalar electrocardiograms were recorded with Sanborn direct-writing recorders. Analysis was confined to the assessment of electrical position and the application of simplified criteria for ventricular hypertrophy. Left ventricular hypertrophy was considered to be present if the sum of $S_{\text {in }} V_{1}$ or $V_{2}$ and $R$ in $V_{5}$ or V6 exceeded $35 \mathrm{mV}$, and right ventricular hypertrophy was diagnosed if $R$ exceeded $S$ in VI or V2. Patients with a QRS complex more than 0.12 sec. in duration were excluded.

Vectorcardiograms were obtained with Sanborn equipment, using the Frank (1956) lead system and a high upper frequency cut off ( $3 \mathrm{~dB}$ down at 1000 c.p.s.). The oscilloscope display 
was adjusted to give $I \mathrm{~cm}$. or $2 \mathrm{~cm}$. deflection in response to the $0.5 \mathrm{mV}$ signal on each axis. Drop-shaped timing interruptions at $2.5 \mathrm{msec}$. intervals gave the direction of rotation of the loop. The oscilloscope face was photographed with a Polaroid camera using a timed delay exposure triggered by the previous QRS complex to record the QRS and T loops.

The QRS vector loops were analysed in regard to amplitude, form, sense of rotation, and orientation in both horizontal and frontal planes. Sagittal plane loops were recorded, but were not analysed in detail. The treatment of long and broad loops differed. The axis reported for a long loop is that of the maximum vector, but for a broad loop the half-area vector is used. The width of the loop is measured at the widest point at right angles to the axial vector.

\section{Results}

The patients have been arranged in series from the relative posterior to anterior distribution of the QRS loops. Five groups are recognized, ranging from long posterior loops through open posterior forms, and broad and crossed loops to anterior, rounded forms (Table I). The maximum voltages tended to be small and were usually well within the normal range. Nearly all the patients were in atrial fibrillation and were receiving treatment with digitalis; for this reason no attempt was made to analyse the changes in the $T$ loops.

Group I Long posterior loops, mostly counterclockwise in the horizontal plane, with a crossover in some cases, were found in 15 patients (Table 2 and Fig. 1 ). The maximum voltage was near the upper limit of normal $(2.0$ to $2.6 \mathrm{mV})$ in 5 patients. The horizontal axes ranged from $-25^{\circ}$ to $-85^{\circ}$ but only 4 were beyond $-60^{\circ}$. The width of the horizontal loops was between 0.1 and 0.4 times the length. The frontal axes varied from $+5^{\circ}$ to $+70^{\circ}$, and the frontal loops were less narrow, the width being between 0.1 and 0.8 times the length.

The electrocardiogram showed evidence of left ventricular hypertrophy in 12 of these patients. Severe left ventricular hypertrophy was thought to be present in 12 patients after full assessment, but there was often right ventricular hypertrophy also, and II had a right ventricular systolic pressure above $40 \mathrm{~mm}$. $\mathrm{Hg}$, though only 2 had pressures above $80 \mathrm{~mm}$. Hg.

Two additional patients had long posterior loops but with a more rightward and posterior horizontal axis (Table 2) and were not included in the group. One of these patients had tricuspid valve disease.
TABLE I Summary of measurements of $Q R S$

loops in five groups, and clinical assessment of right and left ventricular hypertrophy

(58 patients)

\begin{tabular}{|c|c|c|c|c|c|c|c|}
\hline $\begin{array}{l}\text { Horizontal } \\
\text { loop pattern }\end{array}$ & $\begin{array}{l}\text { Maximum } \\
\text { or axial } \\
\text { horizontal } \\
\text { voltage }\end{array}$ & $\begin{array}{l}\text { Horizontal } \\
\text { axis }\end{array}$ & $\begin{array}{l}\text { Horizontal } \\
\text { width } \\
\text { ratio }\end{array}$ & $\begin{array}{l}\text { Frontal } \\
\text { axis }\end{array}$ & $\begin{array}{l}\text { Frontal } \\
\text { width } \\
\text { ratio }\end{array}$ & $\begin{array}{l}R V H \\
(0 \text { to } \\
++) \\
\text { mean }\end{array}$ & $\begin{array}{l}L V H \\
(0 \text { to } \\
++) \\
\text { mean }\end{array}$ \\
\hline \multirow{2}{*}{$\begin{array}{l}\text { Group I : } \\
\text { Long } \\
\text { posterior (15) }\end{array}$} & & & & & & & \\
\hline & $\begin{array}{l}1 \cdot 0 \\
\text { to } \\
2 \cdot 6\end{array}$ & $\begin{array}{l}-25^{\circ} \\
\text { to } \\
-85^{\circ}\end{array}$ & $\begin{array}{l}0.1 \\
\text { to } \\
0.4\end{array}$ & $\begin{array}{l}+5^{\circ} \\
\text { to } \\
+70^{\circ}\end{array}$ & $\begin{array}{l}0.1 \\
\text { to } \\
0.8\end{array}$ & 0.9 & $\mathbf{I} \cdot 7$ \\
\hline \multirow{2}{*}{$\begin{array}{l}\text { Group 2: } \\
\text { Open } \\
\text { posterior (2I) }\end{array}$} & & & & & & & \\
\hline & $\begin{array}{l}0.5 \\
\text { to } \\
2.0\end{array}$ & $\begin{array}{l}0 \\
\text { to } \\
-60^{\circ}\end{array}$ & $\begin{array}{l}0.5 \\
\text { to } \\
2.5\end{array}$ & $\begin{array}{l}+15^{\circ} \\
\text { to } \\
+80^{\circ}\end{array}$ & $\begin{array}{l}0.1 \\
\text { to } \\
0.7\end{array}$ & 0.7 & $1 \cdot 5$ \\
\hline \multirow{2}{*}{$\begin{array}{l}\text { Group 3: } \\
\text { Wide } \\
\text { posterior (9) }\end{array}$} & & & & & & & \\
\hline & $\begin{array}{l}0 \cdot 2 \\
\text { to } \\
1 \cdot 2\end{array}$ & $\begin{array}{l}-20^{\circ} \\
\text { to } \\
-130^{\circ}\end{array}$ & $\begin{array}{l}3 \\
\text { to } \\
\text { 10 }\end{array}$ & $\begin{array}{l}+50^{\circ} \\
\text { to } \\
+150^{\circ}\end{array}$ & $\begin{array}{l}1 \cdot 0 \\
\text { to } \\
6 \cdot 0\end{array}$ & 0.9 & 0.7 \\
\hline \multirow{2}{*}{$\begin{array}{l}\text { Group 4: } \\
\text { Wide } \\
\text { crossed (8) }\end{array}$} & & & & & & & \\
\hline & $\begin{array}{l}0.3 \\
\text { to } \\
1 \cdot 3\end{array}$ & $\begin{array}{l}+60^{\circ} \\
\text { to } \\
-80^{\circ}\end{array}$ & $\begin{array}{l}4 \\
\text { to } \\
15\end{array}$ & $\begin{array}{l}+100^{\circ} \\
\text { to } \\
+160^{\circ}\end{array}$ & $\begin{array}{l}0.3 \\
\text { to } \\
2 \cdot 2\end{array}$ & $1 \cdot 4$ & 0.8 \\
\hline $\begin{array}{l}\text { Group 5: } \\
\text { Anterior } \\
\text { clockwise (5) }\end{array}$ & $\begin{array}{l}0.5 \\
\text { to } \\
1.5\end{array}$ & $\begin{array}{l}+110^{\circ} \\
\text { to } \\
-170^{\circ}\end{array}$ & $\begin{array}{l}0.8 \\
\text { to } \\
7\end{array}$ & $\begin{array}{l}+110^{\circ} \\
\text { to } \\
+150^{\circ}\end{array}$ & $\begin{array}{l}0.5 \\
\text { to } \\
2.4\end{array}$ & $2 \cdot 0$ & $1 \cdot 2$ \\
\hline
\end{tabular}

Group 2 Open posterior loops were found in 21 patients (Table 3 and Fig. 2). The maximum voltage in the horizontal plane was never more than $2.0 \mathrm{mV}$ in these patients. The loops were more to the left than in Group I; the horizontal axis was between 0 and $-60^{\circ}$, and was $-40^{\circ}$ or more posterior than this in 7 patients. The width of the horizontal loop was between 0.5 and 2.5 times the length. The frontal axis was between $+15^{\circ}$ and $+80^{\circ}$, and the width was from 0.1 to 0.7 times the length in all but 3 patients, i.e. a long, narrow frontal loop was usually found in this group. Two patients with relatively wide loops showed the 'pie-plate' pattern in the horizontal plane.

The electrocardiogram indicated left ventricular hypertrophy in 8 of these patients. Severe left ventricular hypertrophy was thought to be present in II patients, and there was the same tendency to right ventricular hypertrophy as in the previous group; II patients had right ventricular systolic pressures above $40 \mathrm{~mm}$. $\mathrm{Hg}$, and in two $80 \mathrm{~mm}$. $\mathrm{Hg}$ was exceeded. One other patient, with tricuspid valve disease, showed an open posterior loop but with a right posterior axis in the horizontal plane, and is listed in Table 3 though not included in the group.

Group 3 Wide posterior loops, counterclockwise in the horizontal plane, were pres- 
ent in 9 patients (Table 4, and Fig. 3). The half-area axis in the horizontal plane was from $-20^{\circ}$ to $-130^{\circ}$ and the axial voltage from 0.2 to $\mathrm{I} \cdot 2 \mathrm{mV}$. The width of the QRS loop was from I.I to $4 \cdot 1 \mathrm{mV}$, and the width was between 3 and ro times the narrow axis. The frontal loop was similar with a tendency to a right axis, $+50^{\circ}$ to $+150^{\circ}$, axial voltage 0.5 to $\mathrm{I} .5 \mathrm{mV}$, width $\mathrm{I} \cdot 0$ to $4.5 \mathrm{mV}$, and width ratio $I$ to 6 times the narrow axis.

The electrocardiogram showed left ventricular hypertrophy in 3 patients, but only one was thought to have serious left ventricular enlargement on clinical grounds. There was electrocardiographic evidence of right ventricular hypertrophy in 6 patients. Right ventricular systolic pressures above $80 \mathrm{~mm}$. $\mathrm{Hg}$ were found in 2 patients, but 4 other patients had tricuspid valve disease.

Group 4 Wide crossed horizontal loops, close to an oblique or transverse axis, were found in 8 patients (Table 4 and Fig. 4). The horizontal half-area vector was widely scattered in this group, because of the crossover. The width of the loop varied from $\mathrm{I} \cdot 3$ to $2.7 \mathrm{mV}$, and was from 4 to 15 times the narrow diameter. The frontal axis was between $+100^{\circ}$ and $+160^{\circ}$, indicating considerable right axis deviation. The axial voltage was between 0.8 and $\mathrm{I} .7 \mathrm{mV}$ and the width was between 0.3 and 2.2 times the axial voltage.

The electrocardiogram indicated left ventricular hypertrophy in 3 patients and right ventricular hypertrophy in 4 patients. The right ventricular systolic pressure was over $80 \mathrm{~mm} . \mathrm{Hg}$ in 3 patients. The tendency is to right ventricular dominance in this group.

Group 5 Anterior clockwise horizontal loops were found in 5 patients with severe right ventricular hypertrophy (Table 4 and Fig. 5). The horizontal axis was to the right, between $+110^{\circ}$ and $-170^{\circ}$, and the voltage varied from 0.5 to $1.5 \mathrm{mV}$. The width of the horizontal loop was between 0.8 and 7.0 times the axial voltage. The frontal axis was between $+110^{\circ}$ and $+150^{\circ}$, the voltage from 0.6 to $2.2 \mathrm{mV}$, and the width from 0.5 to 2.4 times the axial voltage. Left ventricular hypertrophy was present on the electrocardiogram in 3 patients, and 2 of these, with I other patient, were thought to have serious left ventricular hypertrophy on clinical grounds in addition to the very severe right ventricular hypertension found in the whole group. Four of the patients had electrocardiographic evidence, in the ratio of $R$ to $S$ in VI, of right ventricular hypertrophy.
FIG. I $A$ scalar electrocardiogram and

Frank system vectorcardiogram from Group I

(No. 67) showing the long posterior counterclockwise QRS loop in the horizontal plane associated with severe left ventricular hypertrophy. Horizontal $(H)$, frontal $(F)$, and right sagittal $(S)$ vector loops are shown, and the standardization mark is $0.5 \mathrm{mV}$. Dropshaped timing interruptions show the direction of inscription of the loops.
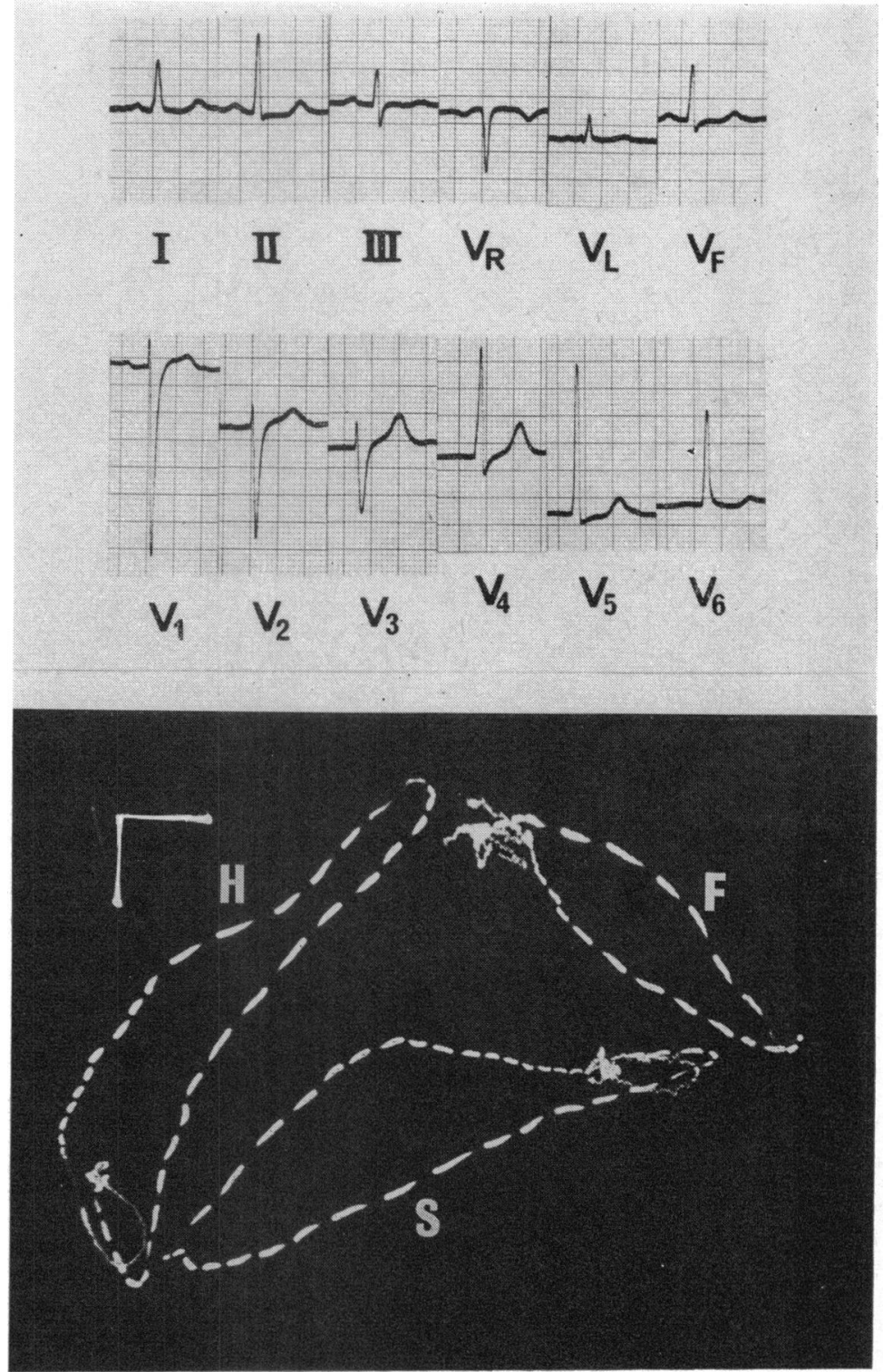
TABLE 2 Group I: Long posterior QRS loops (I 5 patients)

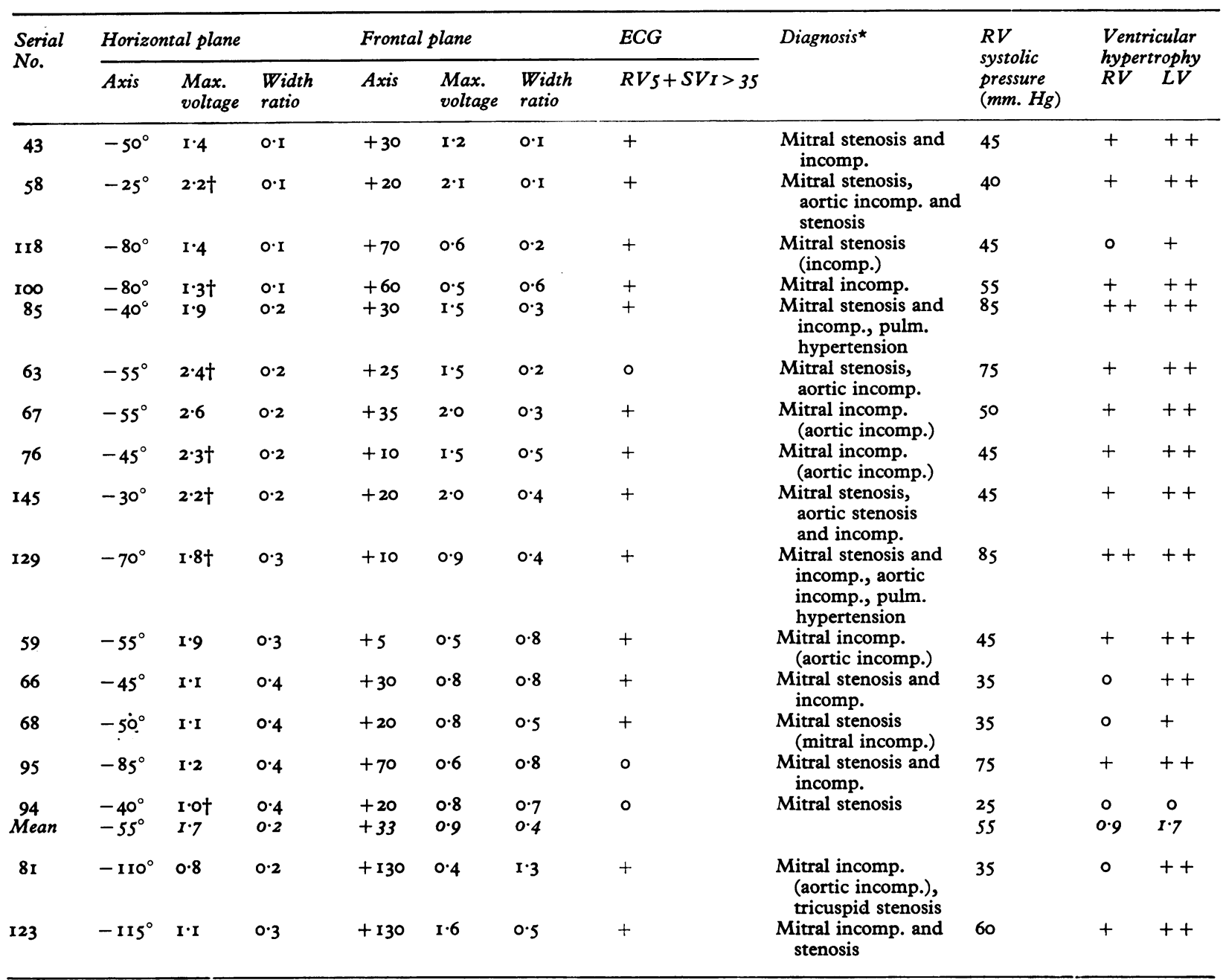

+ Crossed loop

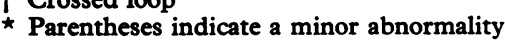

\section{Discussion}

Studies of the scalar electrocardiogram in patients with mitral valve disease have shown relatively poor correlation between the haemodynamic and electrocardiographic evidence of ventricular hypertrophy (Davies et al., I953; Fraser and Turner, 1955; Morris and Whitaker, 1956; Semler and Pruitt, 1960).

Fraser and Turner (1955) drew attention to the high incidence of a vertical electrical position in patients with mitral stenosis. Imperial et al. (1960) confirmed the finding in both mitral stenosis and mitral incompetence. They found little relation between the electrical axis and the right ventricular pressure, and they suggest that the left atrial enlargement common to both forms of mitral valve disease is responsible for the change in electrical position of the heart. The mechanical effect of left atrial enlargement is unlikely to be responsible for the changes in axis, but an alteration in the intrathoracic electrical field by the addition of a large mass of blood behind the ventricles may play a part. The high electrical conductivity of the blood in the left atrium will tend to augment the posterior and inferiorly directed forces to give the impression of a more vertical and posterior electrical position of the heart.

It seems likely that the abnormal inferior and posterior electrical axis in mitral valve disease makes the recognition of ventricular 
hypertrophy difficult until a late stage is reached. The situation is analogous to that found in chronic obstructive airways disease, in which the intrathoracic electrical field is distorted by overexpansion of the lungs which have a relatively low electrical conductivity. Under these circumstances the first effect of right ventricular hypertrophy is to reduce the normal posterior forces, and diagnostic changes in the praecordial scalar electrocardiogram do not become evident until anterior forces are produced at a much later stage. In congenital heart disease right ventricular hypertrophy produces electrocardiographic changes at an earlier stage than is seen in mitral valve disease (Massie and Walsh, 1960).

Vector analysis of the changes in the QRS complex allows more detailed assessment of the directional changes during the course of ventricular activation. Since the demonstration by Grishman and Scherlis (1952) that the 'cube' system of vectorcardiography is useful in distinguishing early stages of right ventricular hypertrophy, several studies of patients with mitral stenosis using this technique have been reported. The clockwise anterior QRS loops in the horizontal plane characteristic of right ventricular hypertrophy patterns were found in a large proportion of the patients studied (Donoso et al., 1957), but there was not a close relation to the pulmonary arterial pressure. Other patients showed anteriorly orientated but counterclockwise horizontal loops which probably indicate some degree of right ventricular dominance. Massie and Walsh (I960) described three QRS patterns in patients with mitral stenosis that resembled the appearances found in chronic lung disease. They found posterior rotation of the whole QRS loop in some patients, a figure-of-eight pattern in the horizontal plane in others, and a superior terminal appendix in a third group. These appearances are attributed to the progressive effect of right ventricular hypertrophy on the posteriorly directed QRS loop produced by the alterations in intrathoracic electrical field discussed in the previous paragraph.

Since these studies, the introduction of the corrected electrode system of Frank (1956) has shown that the 'cube' system gives undue weight to anterior electrical forces so that the effects of right ventricular hypertrophy are exaggerated. Taymor, Hoffman, and Henry (1964) studied 29 patients with mitral stenosis using the Frank system and found posterior displacement of the QRS loop in many patients. The Frank electrode
FIG. 2 Electrocardiogram and vectorcardiogram from Group 2 (No. 78 ) showing an open posterior counterclockwise horizontal QRS loop suggesting left ventricular dominance.
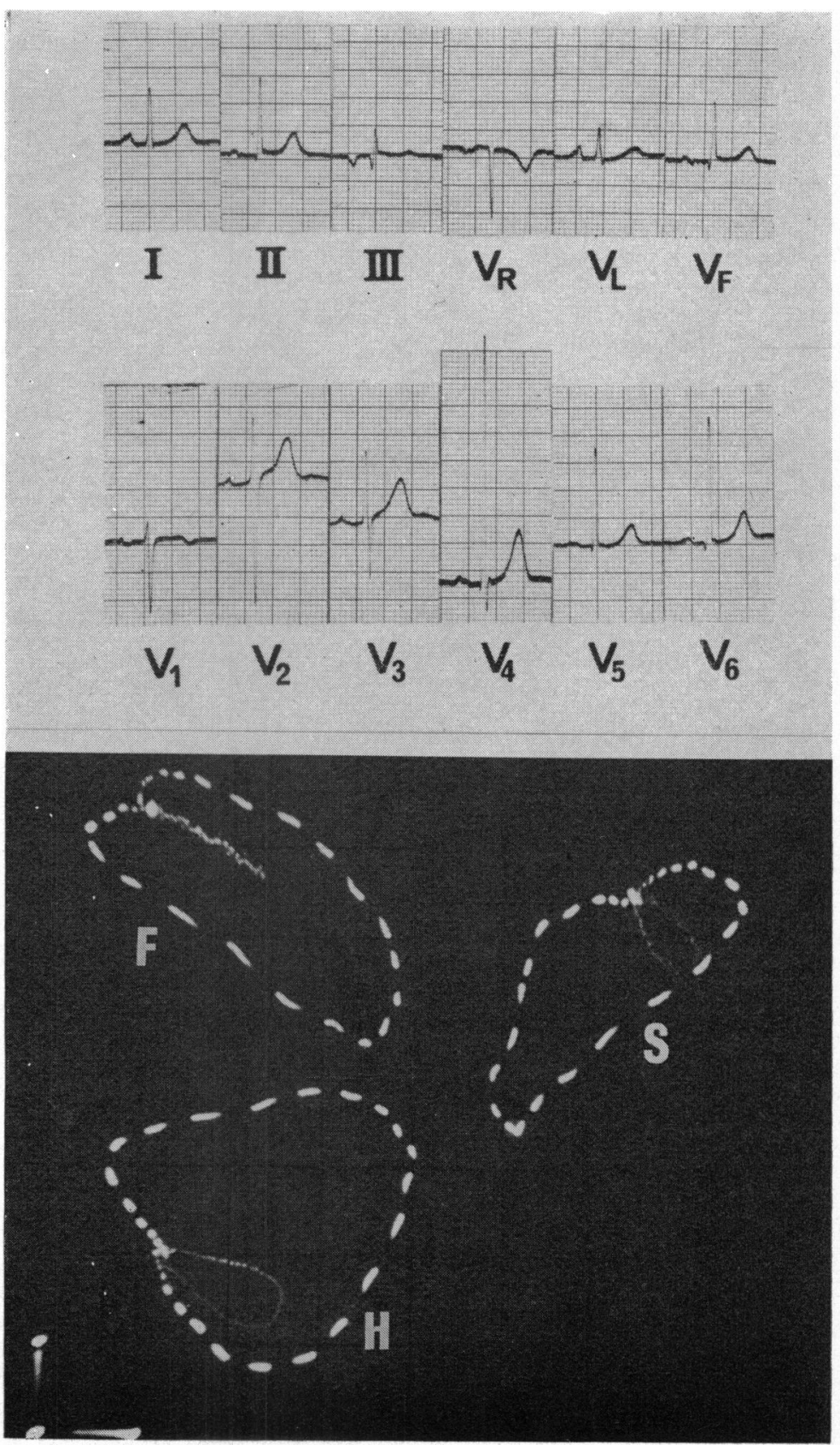
TABLE 3 Group 2: Open posterior $Q R S$ loops (2I patients)

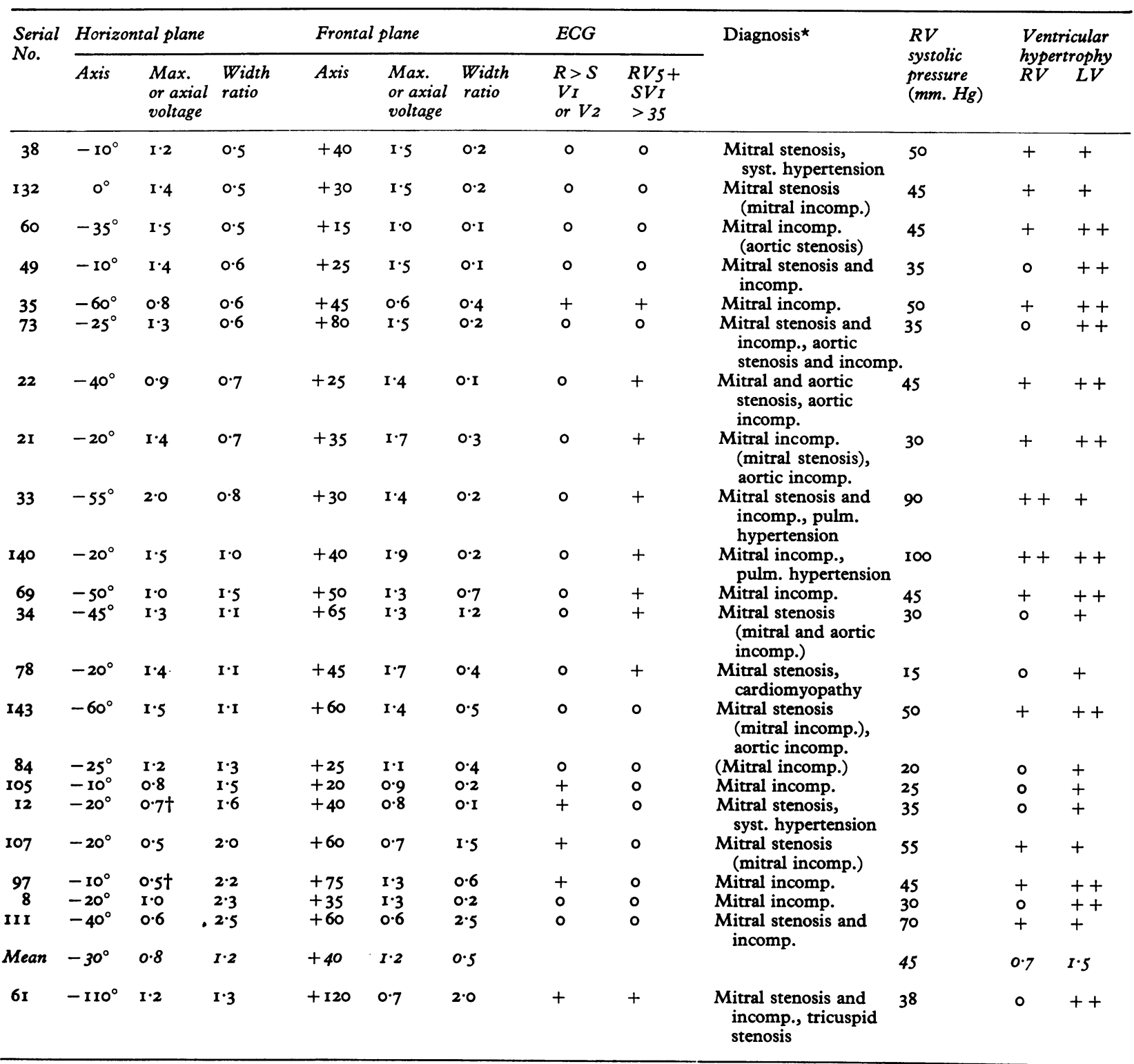

† 'Pie-plate' loop

^ Parentheses indicate a minor abnormality

system will favour the appearance of this pattern in the less severe degrees of right ventricular hypertrophy instead of the anterior clockwise loops found with the 'cube' system.

The diagnosis of ventricular hypertrophy in Frank vectorcardiograms is often difficult. Clear-cut abnormalities may be present, but the normal range of $Q R S$ voltage and axis is wide (Bristow, 196I; Forkner, Hugenholtz, and Levine, 196I), and lesser degrees of hypertrophy may be difficult to detect. Maximum anterior or rightward voltage exceeding the maximum posterior or leftward voltage may be used as evidence of right ventricular hypertrophy (Taymor et al., 1964; Hugenholtz and Gamboa, 1964). Lal, 
Fletcher, and Binnion (1969) found convincing evidence of right ventricular hypertrophy on this basis in the patients with mitral stenosis in their study, but these criteria are difficult to apply when both ventricles are hypertrophied, and the value of the vectorcardiogram in revealing alterations in the direction of QRS forces throughout the activation process is lost if these methods are used exclusively. Toole, von der Groeben, and Spivack (1962) suggested that changes in the shape of the QRS loop might be a guide to the presence of ventricular hypertrophy before voltage abnormalities become apparent.

The criteria proposed for combined ventricular hypertrophy rely on the diagnosis of hypertrophy of one ventricle in an unusual electrical position or on the recognition of abnormally large right and left ventricular forces at different times during the QRS complex. The frequent delay of right ventricular activation in right ventricular hypertrophy may allow the diagnosis of combined ventricular hypertrophy, a large leftwards initial vector being followed by large rightward forces later. Alternatively early anterior forces from the right ventricle may be followed by later posterior forces from the left ventricle, as in the 'pie-plate' loop which corresponds to the large praecordial RS pattern. It is suggested that cancellation of the abnormal forces from the two ventricles may occur in combined hypertrophy, but reference to the direction of the activation fronts in the two ventricles shows this theory to be only, at best, a partial explanation. Large initial forces may sometimes be seen in combined ventricular hypertrophy, giving a deep $Q$ in the left praecordial leads (Marsico et al., 1955), perhaps indicating a delay of the usual change to a posterior direction of the mean $Q R S$ vector because of abnormally large anterior forces from the right ventricle, rather than septal hypertrophy as often suggested.

Scalar electrocardiographic diagnosis of combined left and right ventricular hypertrophy in mitral valve disease is unsatisfactory. Fraser and Turner (1955) studied 22 patients with necropsy confirmation of hypertrophy in both ventricles. The electrocardiogram was normal in 6, showed right ventricular hypertrophy in $I I$, and left ventricular hypertrophy in 2 ; combined ventricular hypertrophy was diagnosed from the electrocardiogram in only 3 patients. They indicate that right ventricular hypertrophy with a horizontal electrical position is not valid evidence of combined ventricular hypertrophy. The converse, left ventricular hypertrophy
FIG. 3 Electrocardiogram and vectorcardiogram from Group 3 (No. 7I) showing the wide posterior counterclockwise horizontal $Q R S$ loop associated with moderate right and left ventricular hypertrophy.

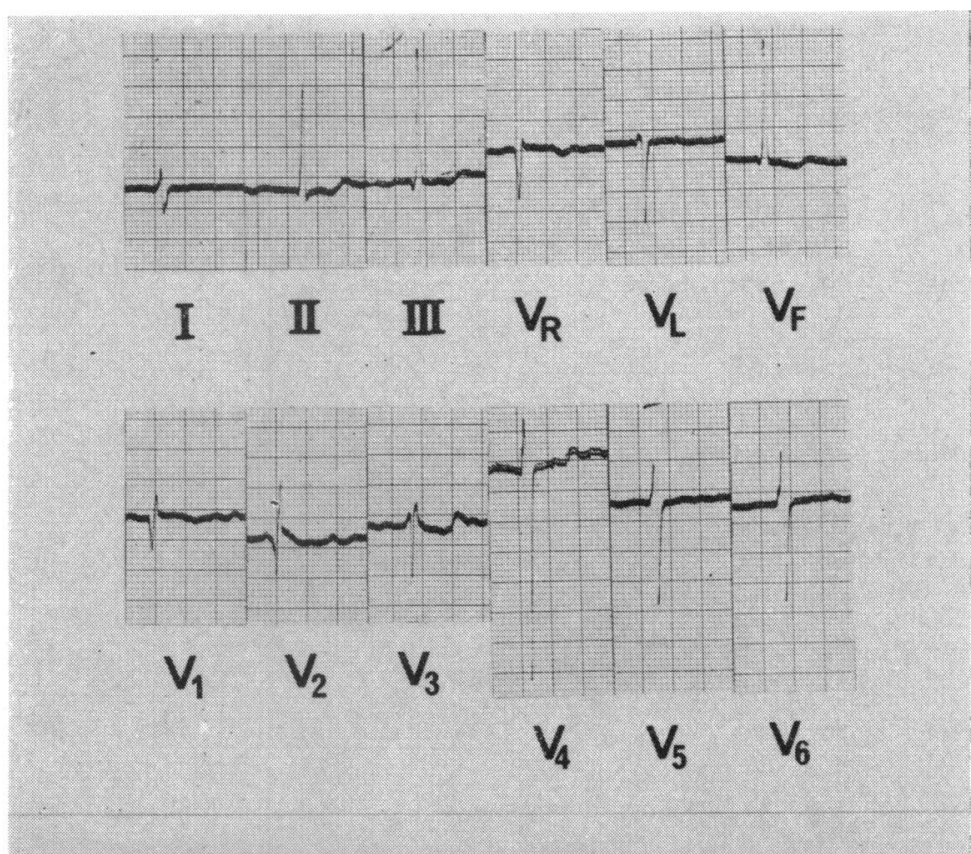


TABLE 4 Groups 3, 4, and 5: Wide posterior, crossed, and anterior QRS loops (22 patients)

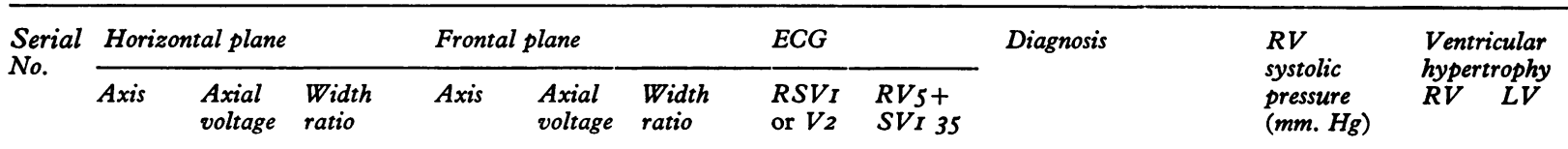

Group 3: Wide posterior $Q R S$ loops (9 patients)

$\begin{array}{cccccccccc}70 & -80 & 0.2 & 10 & +90 & 0.5 & 3 & + & 0 \\ 71 & -130 & 0.2 & 7 & +110 & 1.3 & 1.0 & + & + \\ 65 & -50 & 0.4 & 6 & +50 & 0.6 & 4 & + & 0 \\ 10 & -110 & 0.3 & 5 & +110 & 0.8 & 2.8 & + & 0 \\ & & & & & & & & \\ 125 & -90 & 0.5 & 5 & +120 & 0.6 & 4 & + & 0 \\ 31 & -20 & 0.6 & 4 & +150 & 0.5 & 3 & 0 & 0 \\ 136 & -70 & 0.4 & 4 & +100 & 0.5 & 3 & 0 & 0 \\ 24 & -70 & 0.6 & 4 & +60 & 0.5 & 4 & 0 & + \\ 52 & -70 & 1.2 & 3 & +100 & 1.5 & 6 & + & + \\ M e a n & -75 & 0.5 & 5 & +100 & 0.8 & 3 & \end{array}$

Mitral stenosis and 25 incomp., tricuspid stenosis

Mitral stenosis and incomp., tricuspid stenosis

Mitral stenosis, $\quad 105$ pulm. hypertension

Mitral and aortic stenosis, aortic incomp., tricuspid stenosis

Mitral stenosis 1 I (mitral incomp.), pulm. hypertension

Mitral stenosis

Mitral stenosis (aortic incomp.)

Mitral stenosis

(aortic incomp.),

tricuspid stenosis

Mitral stenosis, syst. hypertension

\section{ए}

Group 4: Wide crossed $Q R S$ loops (8 patients)

$\begin{array}{rrrrrrrrrr}13 & +60 & 1 \cdot 0 & 4 & +110 & 0.9 & 2.0 & + & + \\ 18 & +110 & 0.3 & 6 & +100 & 0.8 & 0.8 & + & 0 \\ 9 & +140 & 1 \cdot 0 & 7 & +135 & 0.9 & 1 \cdot 0 & 0 & + \\ 42 & -80 & 0.3 & 8 & +150 & 1 \cdot 0 & 1 \cdot 5 & 0 & + \\ 93 & -150 & 1.3 & 9 & +160 & 1 \cdot 7 & 0.3 & 0 & 0 \\ 51 & -145 & 1 \cdot 0 & 12 & +140 & 1.0 & 2.2 & + & 0 \\ 109 & +150 & 1 \cdot 2 & 13 & +110 & 1 \cdot 3 & 1 \cdot 0 & + & 0 \\ 53 & -160 & 0.3 & 15 & +140 & 1.3 & 1.2 & 0 & 0 \\ M e a n & +170 & 0.8 & 9 & +130 & 1.1 & 1.3 & & \end{array}$

Mitral stenosis and 100 incomp., pulm. hypertension

Mitral stenosis

Mitral stenosis, pulm. hypertension

Mitral stenosis and incomp., pulm. hypertension

Mitral and aortic stenosis, mitral incomp.

Mitral stenosis

Mitral stenosis, pulm. hypertension

Mitral stenosis

45
105
30

115

55

20

40

4

50

$0.9 \quad 0.7$

Group 5: Wide anterior clockwise QRS loops (5 patients)

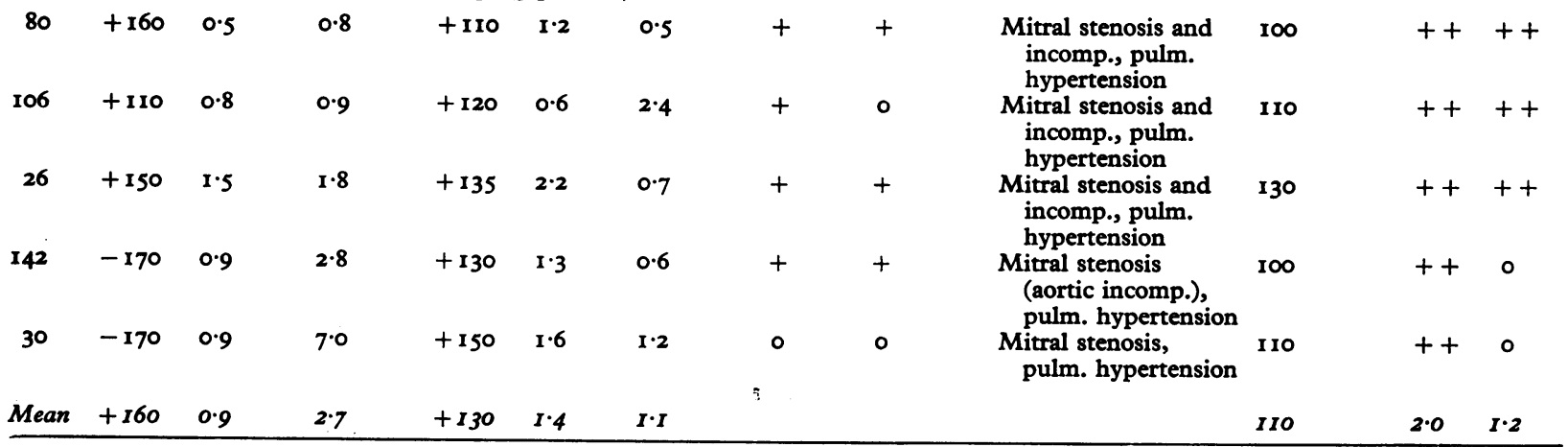


with a vertical heart, is frequently seen in isolated aortic stenosis, though more extreme right axis deviation is more convincing evidence of associated right ventricular hypertrophy (Pagnoni and Goodwin, 1952).

In view of the difficulties in defining arbitrary criteria for the assessment of the hypertrophy in each ventricle when both are abnormal, the vectorcardiographic patterns in the present study have been analysed to determine the relation to the degree of left and right ventricular hypertrophy estimated on clinical and haemodynamic grounds. A continuous gradation from posterior to anterior direction of the QRS loop is evident, but five groups have been defined arbitrarily for convenience of description.

The first group, with long posterior loops (Fig. I), probably represents left ventricular dominance, though only a few patients had maximal QRS voltages beyond the normal upper limit of approximately $2.0 \mathrm{mV}$ (Romhilt, Greenfield, and Estes, 1968). Crossing of the QRS loops to give a terminal clockwise part may be evidence of myocardial damage interfering with normal conduction in the ventricle. Clinical and haemodynamic assessment suggested serious left ventricular hypertrophy in most of these patients, though right ventricular hypertrophy was often present in addition. The scalar electrocardiogram was more successful than the vectorcardiogram in diagnosing left ventricular hypertrophy in this group, suggesting that significant local effects from the left ventricle are detected with conventional praecordial leads which are lost with the corrected orthogonal Frank electrode system.

The second group (Fig. 2), with open posterior loops, closely resembles the records from normal subjects. The more posteriorly directed loops in this group probably correspond to the pattern described by Massie and Walsh (1960). Serious left ventrioular hypertrophy was the usual finding in these patients and there was often right ventricular hypertrophy also. The voltage criteria for left ventricular hypertrophy were not evident in the vectorcardiogram though the conventional electrocardiogram often showed large QRS voltages. The electrocardiographic suggestion of right ventricular hypertrophy in 4 patients was not supported by other evidence. The wider QRS loop in these patients, in comparison to the first group, may be an indication of a greater effect from the hypertrophied right ventricle. In 2 patients with particularly wide loops the 'pie-plate' pattern described as characteristic of combined ventricular hypertrophy was found.

FIG. 4 Electrocardiogram and vectorcardiogram from Group 4 (No. 42) showing a wide crossed horizontal $Q R S$ loop suggesting right ventricular dominance
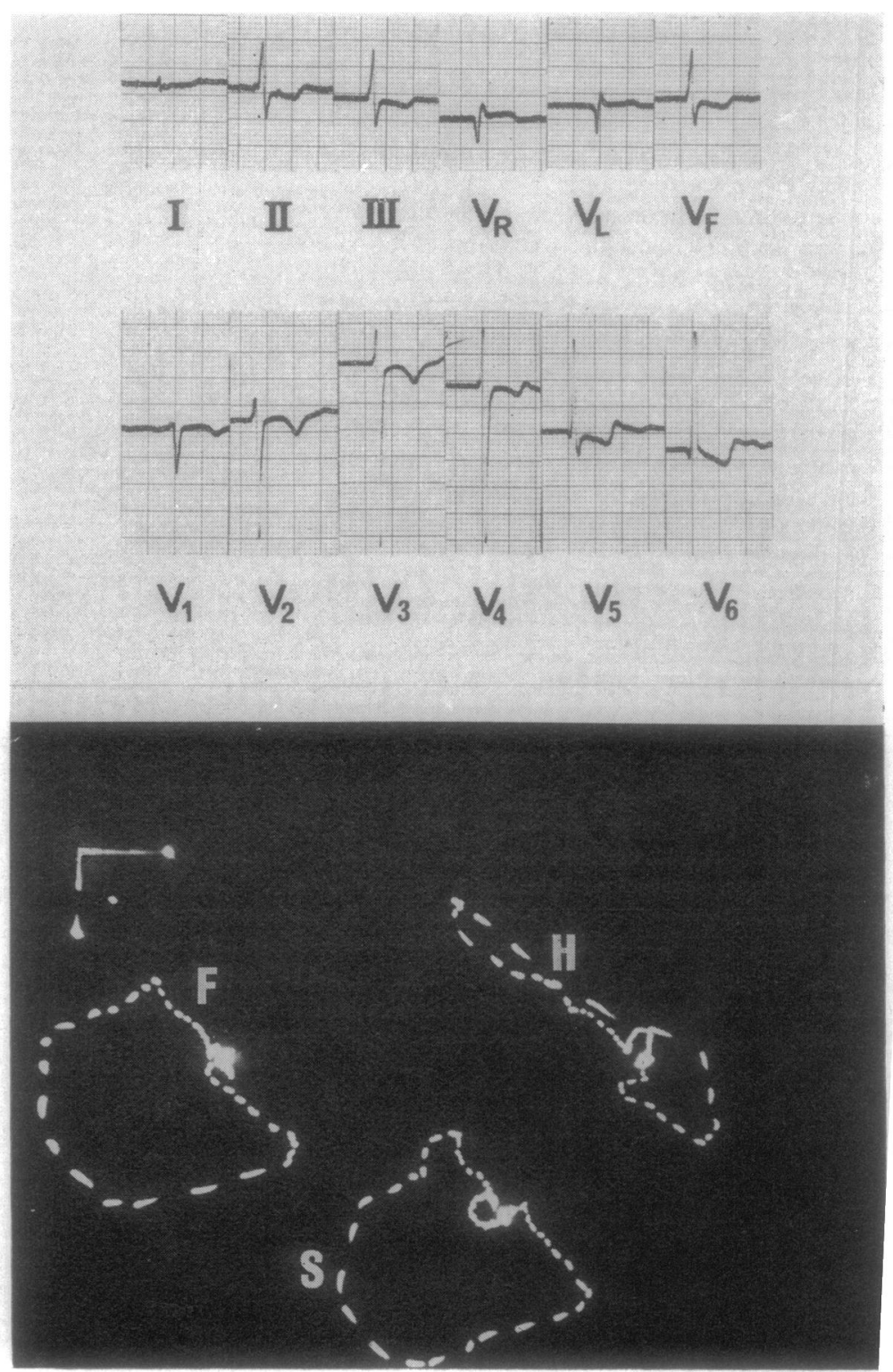
The wide posterior loops of the third group (Fig. 3) probably indicate a greater degree of right ventricular dominance. Clini$\mathrm{cal}$ and haemodynamic studies suggested moderate hypertrophy of each ventricle in some of these patients, but in others there appeared to be right ventricular hypertrophy only, or moderate left ventricular hypertrophy accompanied by serious tricuspid valve disease. The QRS pattern may be produced by a balanced contribution from the two ventricles during the early parts of the activation process, with initial large septal forces and a later posterior and rightwards component. The inferior direction of the frontal loop in these patients is a further indication of the effects of right ventricular hypertrophy. The QRS loop described by Massie and Walsh (I960) as having a posterior superior appendix would be included here. Both left and right ventricular hypertrophy were found in the scalar electrocardiograms.

The high incidence of tricuspid valve disease in these patients is striking. The only other patients with organic tricuspid valve lesions that were studied had more left ventricular disease and resembled the preceding two groups, but in each case there was an unduly rightward displacement of the maxi mal vector. The unusual rightwards forces found in association with tricuspid valve disease may be produced by the high electrical conductivity of the large mass of blood in the dilated right atrium.

The fourth pattern (Fig. 4), of a wide crossed horizontal loop and an inferiorly directed frontal loop, is characteristic of right ventricular dominance, as is evident from the clinical and haemodynamic findings. The pattern indicates a later stage of anterior displacement of the middle part of the QRS loop due to increasing right ventricular forces. The electrocardiogram showed evidence of right ventricular hypertrophy in the praecordial leads in only half these patients, but was more successful in diagnosing associated left ventricular hypertrophy.

The wide anterior clockwise QRS loops of the fifth group (Fig. 5) are a clear indication of severe right ventricular hypertrophy, and represent the final stage of anterior displacement of the loop. Very severe right ventricular hypertrophy was found in all these patients, though not always evident in the praecordial leads of the electrocardiogram. The large inferior and rightwards frontal loop in these patients would lead to considerable right axis deviation in the conventional electrocardiogram which must give rise to the suspicion of serious right ventricular
FIG. 5 Electrocardiogram and vectorcardiogram from Group 5 (No. 142) showing the anterior clockwise horizontal QRS loop associated with severe right ventricular hypertrophy
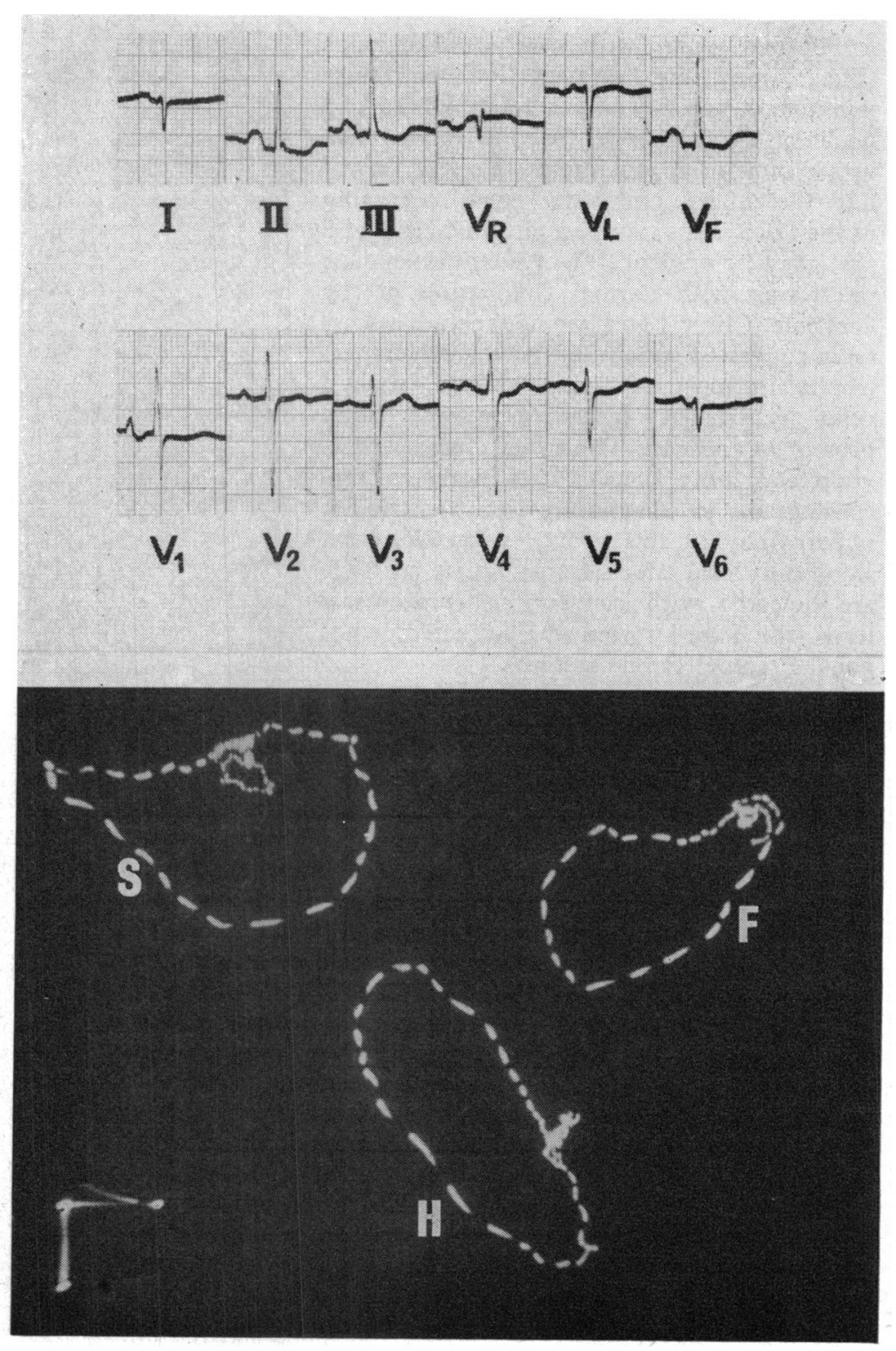
hypertrophy. The presence of left ventricular hypertrophy in addition could not be predicted from the vectorcardiogram, but was sometimes evident in the scalar electrocardiographic leads.

\section{Conclusions}

The relative predominance of right and left ventricular hypertrophy in mitral valve disease can be predicted from the vectorcardiogram with moderate success. Severe right ventricular dominance is more easily diagnosed from the vectorcardiogram than from the scalar electrocardiogram. The abnormal rightward forces associated with tricuspid valve disease can also be recognized. Previous criteria for the vectorcardiographic diagnosis of left ventricular hypertrophy are, however, insensitive in the recognition of left ventricular dominance in mitral valve disease, though the conventional electrocardiogram is often successful. From this study it is apparent that the long posterior loop and the open posterior loop provide evidence of serious left ventricular hypertrophy in the presence of right ventricular hypertrophy even when the $Q R S$ voltage is not abnormally large.

The findings confirm the value of the vectorcardiogram in the analysis of complex disturbances of ventricular activation. The effect of distortion of the intrathoracic electrical field by enlargement of the left or right atrium is evident. It is suggested that interpretation based on the spatial pattern of the QRS loop may be of more value than the application of voltage criteria in the recognition of combined ventricular hypertrophy.

\section{References}

Bristow, J. D. (196I). A study of the normal Frank vectorcardiogram. American Heart fournal, 6r, 242.

Davies, L. G., Goodwin, J. F., Steiner, R. E., and van Leuven, B. D. (1953). The clinical and radiological assessment of the pulmonary arterial pres- sure in mitral stenosis. British Heart fournal, 15, 393.

Donoso, E., Jick, S., Braunwald, E., Lamelas, M., and Grishman, A. (1957). The spatial vectorcardiogram in mitral valve disease. American Heart fournal, 53, 760 .

Forkner, C. E., Hugenholtz, P. G., and Levine, H. D. (196I). The vectorcardiogram in normal young adults. Frank lead system. American Heart fournal, 62, 237.

Frank, E. (1956). An accurate, clinically practical system for spatial vectorcardiography. Circulation, 13, 737.

Fraser, H. R. L., and Turner, R. (1955). Electrocardiography in mitral valvular disease. British Heart fournal, 17, 459.

Grishman, A., and Scherlis, L. (1952). Spatial Vectorcardiography. W. B. Saunders, Philadelphia.

Hugenholtz, P. G., and Gamboa, R. (I964). Effect of chronically increased ventricular pressure on electrical forces of the heart. Circulation, 30, $5 \mathrm{II}$.

Imperial, E. S., Bendezu, J., and Zimmerman, H. A (1960). Electrocardiographic analysis of pure mitral valvular disease: a study based on 57 cases with open-heart operation. American Heart fournal, 60, 705 .

Lal, S., Fletcher, E., and Binnion, P. (1969). Frank vectorcardiogram correlated with haemodynamic measurements. Quantitative analysis. British Heart fournal, 31, 15 .

Marsico, F., Peñaloza, D., Tranchesi, J, Limón, R. and Sodi-Pallares, D. (1955). The electrocardiogram in ventricular septal defect: scalar and vectorial analysis of 32 cases. American Heart fournal, 49, 188 .

Massie, E., and Walsh, T. J. (1960). Clinical Vectorcardiography and Electrocardiography. Year Book Publishers, Chicago.

Morris, T. L., and Whitaker, W. (1956). The ventricular pattern in the right precordial leads in mitral stenosis. American Heart fournal, 52, 738.

Pagnoni, A., and Goodwin, J. F. (1952). The cardiographic diagnosis of combined ventricular hypertrophy. British Heart fournal, 14, 451.

Romhilt, D. W., Greenfield, J. C., and Estes, E. H. (1968). Vectorcardiographic diagnosis of left ventricular hypertrophy. Circulation, 37, 15.

Semler, H. J., and Pruitt, R. D. (1960). An electrocardiographic estimation of the pulmonary vascular obstruction in 80 patients with mitral stenosis. American Heart fournal, 59, 541.

Taymor, R. C., Hoffman, I., and Henry, E. (1964). The Frank vectorcardiogram in mitral stenosis. A study of 29 cases. Circulation, 30, 865.

Toole, J. G., von der Groeben, J., and Spivack, A. P. (1962). The calculated tempero-spatial heart vector in proved isolated left ventricular overwork. American Heart fournal, 63, 537. 